\title{
Avisos publicitarios en verso en los primeros años de la revista Caras y Caretas (1898-1900): entre el humor, la política y la persuasión
}

\author{
María Soledad PESSI ${ }^{1}$ \\ Universidad Nacional del Sur
}

\section{RESUMEN:}

En la historiografía de la publicidad argentina, el período comprendido entre los últimos años del siglo XIX y las primeras décadas del siglo XX posee particular importancia ya que comienzan a formarse y articularse en estos años los pasos iniciales de la publicidad moderna en una sociedad bajo la presión de la inmigración masiva, la clase media emergente y la clase trabajadora alentada por la movilidad social.

Este trabajo analiza avisos publicitarios gráficos en verso en los primeros años de publicación de la revista Caras y Caretas (1898-1900) como un fenómeno en el camino a la autonomía de la publicidad: desde el humor y la política hacia la publicidad moderna. Este estilo retórico cambió su forma radicalmente en 1900 cuando las revistas argentinas comenzaron a llenarse de anuncios.

El propósito de este trabajo es explorar la forma y funciones de este tipo de avisos en Caras y Caretas (1898-1900) desde la perspectiva de la sociolingüística histórica aplicada al discurso publicitario ${ }^{2}$.

PALABRAS CLAVE: publicidad; avisos publicitarios en verso; autonomía; revista Caras y Caretas; Argentina.

TITLE: Ads in verse in the early years of the magazine Caras y Caretas (1898-1900): between humour, politics and persuasion

\section{ABSTRACT:}

In the historiography of argentine advertising, the period from the late nineteenth and early twentieth century is of particular importance, since the first steps of the modern advertising began to form and articulate in

1 María Soledad Pessi es Licenciada y Profesora en Letras, especializada en Lingüística (Universidad Nacional del Sur, Argentina). Se desempeña como investigadora en el Centro de Estudios Lingüísticos Dra. Ma. Beatriz Fontanella de Weinberg y forma parte del equipo docente de la cátedra Gramática Española de la carrera de Letras de esa universidad. Ha publicado el resultado de sus investigaciones sobre el discurso publicitario en eventos y revistas nacionales e internacionales.

Correo electrónico: soledad.pessi@uns.edu.ar

2 GIESZINGER, S. (2001): The history of advertising language: the advertisements in The Times from 1788 to 1996, Frankfurt, Peter Lang; GöRLACH, M. (2002): «A linguistic history of advertising, 17001890», en Fanego, T. (eds), Sounds, Words, Texts and Change, Amsterdam, Benjamins, pp.83-104; GörLACH, M. (2004): Text types and the history of English, Berlin and New York, Mouton de Gruyter y GotTI, M. (2005): «Advertising Discourse in Eighteenth-century English Newspapers'», en Skaffari, J., Peikola, M., Carroll, R., Hiltunen, R., Warvik, B. (eds), Opening Windows on Texts and Discourses of the Past, Ámsterdam, Benjamins, pp.23-38. 
those years in a society undergoing the pressure of massive immigration, the emerging middle class, and a working class encouraged by social mobility.

This paper analyzes the advertisements graphics in verse in the early years of the magazine Caras $y$ Caretas (1898-1900) as a phenomenon on the way to the autonomy of advertising: from humour and politics to the modern advertising. This rhetorical style radically changed form 1900 when argentine magazines began charging for advertising.

The purpose of this paper is to explore the form and functions of this type of ads in Caras y Caretas, 1898-1900, from historical sociolinguistics applied to advertising.

KEY WORDS: advertising; ads in verse; autonomy; Caras y Caretas magazine; Argentina

\section{Introducción}

Quienes se han ocupado del estudio de los orígenes de la publicidad señalan que el surgimiento de este fenómeno puede rastrearse desde tiempos remotos ${ }^{3}$. Aún así, acuerdan en que es a fines del siglo XIX cuando comienza su transición hacia un formato con características modernas que incluye el desarrollo de sus distintos constituyentes (titular, cuerpo del texto y cierre) y una particular dinámica entre los elementos ícono-verbales ${ }^{4}$. En forma paralela, en las publicaciones de la época se produce un abandono paulatino del espacio dedicado a los anuncios clasificados y avisos simples y, como contrapartida, un crecimiento sostenido de la cantidad de anuncios con características modernas. Además, la ubicación de los avisos publicitarios en secciones fijas -que la mostraban como un segmento secundario- va desapareciendo en pos de una distribución más flexible que abarca diferentes partes de diarios y revistas. Se suma a este proceso, la importancia creciente de la prensa y la incipiente profesionalización de las empresas dedicadas a la actividad publicitaria ${ }^{5}$.

3 Sobre los orígenes de la publicidad pueden consultarse los siguientes estudios: SÁNCHEZ GUZMÁN, J. (1976): Breve historia de la publicidad, Madrid, Pirámide y CHECA GODOY, A. (2007): Historia de la publicidad, La Coruña, Netbiblo.

4 Sobre los distintos períodos por los que atraviesa la publicidad y principalmente la transición que se produce a mediados del siglo XIX pueden consultarse los estudios de CARO, A. (2009): «Una fase decisiva en la evolución de la publicidad: la transición del producto a la marca», Pensar la publicidad. Revista Internacional de Investigaciones Publicitarias, 3 (2), Madrid y Valladolid, 109-132 y OJEDA, A. (2009): «Del reclame a la publicidad. La transición hacia la modernidad publicitaria en la prensa periódica argentina entre 1862 y 1885», Pensar la publicidad. Revista Internacional de Investigaciones Publicitarias, 3 (2), Madrid y Valladolid, 133-148. Sobre los distintos constituyentes de la publicidad recomendamos la investigación de LEECH, G. (1966): English in advertising. A linguistic study of advertising in Great Britain, London, Longmans, un clásico sobre el tema. En relación con la evolución de los distintos segmentos del aviso publicitario resulta muy interesante el trabajo sobre la publicidad inglesa de GIESZINGER, S. (2001): The history of advertising language: the advertisements in The Times from 1788 to 1996, Frankfurt, Peter Lang.

5 Acerca del surgimiento de las agencias de publicidad en Argentina, pueden consultarse GALVÁN Moreno, C. (1944): El periodismo argentino. Amplia y documentada historia desde sus orígenes hasta el presente, Buenos Aires, Claridad; RocCHI, F. (2000): «El péndulo de la riqueza: la economía argentina en el período 1880-1916», en Lobato, M. (dir.), Nueva Historia Argentina, tomo 5, Buenos Aires, Sudamericana; y CHECA GODOY, A. (2007): Historia de la publicidad, España, Netbiblo. 
El cambio se da, entonces, como consecuencia de una serie de factores tanto externos como internos al mismo fenómeno que repercuten en la configuración de los avisos $^{6}$.

En la Argentina, el período comprendido entre fines del siglo XIX y los primeros años del siglo XX representa el inicio de un momento de transición entre las formas discursivas tradicionales y las modernas que se consolidarán hacia la década de 1930.

Como parte de esta transformación, la revista Caras y Caretas -baluarte de la prensa moderna de la Argentina- además de los avisos clasificados y anuncios simples, incluye entre sus páginas anuncios en verso en los dos primeros años de publicación (1898-1900).

La característica singular de estas composiciones será su contenido políticohumorístico puesto de manifiesto tanto a nivel verbal como visual. Trataremos de demostrar que este fenómeno encuentra explicación en el estilo de la publicación, más precisamente, el estilo de sus portadas, que se reproduce en los anuncios en verso de distintos productos.

Consideramos, entonces, que los anuncios en verso son producto de una etapa de transición entre la publicidad tradicional y la moderna, ya que algunos de los recursos utilizados en su construcción resultan novedosos e innovadores para la prensa argentina de la época y serán característicos de la publicidad de etapas posteriores. Pero, por otro lado, la aparición en los avisos en verso de pautas gráficas y verbales que identifican a la revista Caras y Caretas -principalmente por sus portadas- demuestra su dependencia de la publicación en la que se insertan.

La interacción de ambos procesos en un mismo aviso indica, a nuestro parecer, un estado intermedio, de transición, que demuestra la inestabilidad discursiva de la publicidad durante el período bajo estudio.

\section{Orígenes del periodismo en Argentina}

Las primeras revistas que se publicaron en Buenos Aires se vendían por medio de suscripciones o en las imprentas en las que se editaban. El éxito dependía del interés que despertara la publicación y de la fidelidad de sus suscriptores. Muchas publicaciones tuvieron una corta existencia debido a la escasa venta y a la imposibilidad de afrontar los altos costos de producción.

6 Mencionamos a continuación algunos autores que abordan esta temática: ALONSO PIÑEIRO, A. (1974): Breve historia de la publicidad argentina, Buenos Aires, Alzamor; SÁNCHEZ GUZMÁN, J. (1976): Breve historia de la publicidad, Madrid, Pirámide; Leiss, W., Kline, S., Jhally, S. and Boterill, J. (2005): Social communication in advertising. Consumption in the mediated marketplace, 3th. ed., London, Routledge; MADRID CÁNOVAS, S. (2006): Semiótica del discurso publicitario. Del signo a la imagen, Murcia, Universidad de Murcia, Servicio de publicaciones; CHECA GoDOY, A. (2007): Historia de la publicidad, España, Netbiblo; TUNGATE, M. (2007): Adland: a global history of advertising, London, Kogan Page. 
La publicidad no era vista como un medio económico capaz de solventar de forma integral o parcial los costos de la prensa. Por el contrario, en algunas revistas la inserción de avisos era de algún modo un factor mercantil que atentaba contra el verdadero espíritu de la publicación ${ }^{7}$. Con el paso del tiempo, la inclusión de avisos se fue transformando en una acción ineludible.

A fines del siglo XIX se produjeron una serie de cambios de tipo económico, social y político que modificaron sustancialmente la Argentina. Todas estas transformaciones tuvieron honda importancia en el desarrollo de la prensa gráfica, principalmente el aumento demográfico -producto de la llegada de grandes oleadas inmigratorias- y la conformación de una clase media con deseos de movilidad social e ingresos estables. Esta situación redundó en una ampliación de la cantidad de lectores y en la posibilidad de especializar las publicaciones de acuerdo con los distintos intereses de los consumidores. Como indica Rocchi ${ }^{8}$, para los primeros años del siglo XX el mercado de consumó presentó «los primeros signos de masificación».

En este marco de transformaciones, la publicidad fue uno de los pilares que acompañó el desarrollo de la industria gráfica ya que permitía bajar el precio de venta de diarios y revistas $\mathrm{y}$, en consecuencia, ampliar el número de lectores. A corto plazo, la pauta publicitaria de las mencionadas publicaciones aumentó considerablemente en virtud de las ganancias obtenidas. En forma paralela, surgieron las primeras agencias de publicidad, encargadas de sistematizar la actividad que, en principio, era rudimentaria y artesanal.

Por este motivo, los avisos publicitarios no pueden ser considerados únicamente como un tipo de discurso más adentro de las publicaciones gráficas, sino que debe ser analizado como una parte constitutiva de las mismas, asociados en más de una oportunidad a su éxito o fracaso.

En este proceso, los avisos sufrieron una serie de cambios en su estructura que permiten determinar el paso del estilo tradicional hacia el moderno. Las imágenes se transformaron en un elemento importante dentro de la dinámica de los avisos. Un fenómeno similar ocurrió con el resto de los constituyentes, en particular, con

7

A modo de ejemplo, en Las Provincias Ilustradas (1887-1888), una revista cultural, cuyo objetivo era ofrecer información sobre las distintas provincias de la Argentina, no aparece ningún espacio destinado a publicidad en los primeros números. AUZA, N. (1989): «Las provincias ilustradas. 1887-1888», Res Gesta, Buenos Aires, Facultad de Derecho y Ciencias Sociales, Instituto de Historia, 25, enero-junio, quien estudió detalladamente la publicación, afirma que sólo por excepción se incluyen uno o dos avisos por entrega y que su financiamiento se produce fundamentalmente por medio de las suscripciones. Al no ser suficientes, los directivos resuelven incluir avisos comerciales para afrontar los costos: «Recibiremos anuncios a precio convencional, según la posición de las páginas que lleven. Es una medida que dará mayor amplitud pecuniaria, aunque es cierto, debemos confesarlo, que es doloroso ver el aviso de un artefacto confundido con hermosas elucubraciones y preciosas joyas poéticas» (p. 186). Como demuestra el mismo autor, la dirección de la revista cumple con su promesa ya que no existía otra posibilidad de sostén económico. En los números siguientes crece el espacio destinado a los avisos. No obstante esto, la revista deja de publicarse al poco tiempo.

RocCHI, F. (2000): «El péndulo de la riqueza: la economía argentina en el período 1880-1916», en Lobato, M. (dir.), Nueva Historia Argentina, tomo 5, Buenos Aires, Sudamericana. 
el titular. A nivel verbal, se desplegó una amplia gama de recursos para atraer la atención del receptor a quien se trataba de convencer a partir de argumentos racionales sobre las ventajas del producto promocionado, que luego serían reemplazadas por los beneficios de la marca'.

\subsection{La revista «Caras y Caretas»}

La revista Caras y Caretas (1989-1941) inauguró un nuevo estilo en la prensa gráfica porteña de fines del siglo XIX. Marcó una diferencia con el resto de las publicaciones de la época al dirigirse a un público lector amplio y heterogéneo conformado principalmente por la emergente clase media ${ }^{10}$.

Subtitulada como «Semanario festivo, literario, artístico y de actualidades», se publicó por primera vez el 8 de octubre de 1898. Fue testigo de los cambios ocurridos en la sociedad y parte integrante y activa de la invención del proyecto modernizador argentino.

Su modernidad se verifica en los siguientes elementos: ampliación del público lector y conformación de un nuevo piso de lectores en relación con el de las revistas ilustradas de la época, objetivo familiar, cambios en la forma de lectura, contribución a la profesionalización del escritor y del artista, formato novedoso e inclusión de un gran número de anuncios. A estos, Cavalaro ${ }^{11}$ agrega: calidad del papel, primeras fotografías y tratamiento moderno de la composición (abandona el modelo de columnas para incorporar fotos e ilustraciones en medio del texto).

Su historia nace en Uruguay donde su editor, Eustaquio Pellicer, había iniciado una publicación en el año 1890 (1ra. época: 1890-1897). Según documenta Ulanovsky ${ }^{12}$, la revista comenzó a editarse bajo la sociedad formada por Eustaquio Pellicer y Bartolomé Mitre y Vedia, un hijo del fundador del diario La Nación, quien tuvo que renunciar tiempo después debido a presiones ejercidas por su padre, quien consideraba que la participación de su hijo en dicha publicación podía dañar «su imagen, su nombre y la del diario». En su lugar, formaron parte de la sociedad José S. Alvarez, más conocido como «Fray Mocho», y el dibujante español Manuel Mayol.

Como expresión periodística, Caras y Caretas ha sido caracterizada por el diseño de sus imágenes, aspecto que se detecta principalmente en la portada, y por su contenido humorístico-político. La revista tuvo una frecuencia semanal e incluyó

9 Sobre este proceso, puede consultarse CARO, A. (2009): «Una fase decisiva en la evolución de la publicidad: la transición del producto a la marca», Pensar la publicidad. Revista Internacional de Investigaciones Publicitarias, 3 (2), Madrid y Valladolid, 109-132.

10 Beyhaut, G.; Cortés CONDE, R.; Gorostegui, H.; TORRADO, S. (1961): Inmigración y desarrollo económico, Buenos Aires, Universidad de Buenos Aires - Departamento de Sociología.

11 Cavalaro, D. (1996): Revistas argentinas del siglo XIX, Buenos Aires, Asociación Argentina de Revistas (AAER), 128.

12 UlAnOvSKY, C. (1997): Paren las rotativas. Historia de los grandes diarios, revistas y periodistas argentinos, Buenos Aires, Espasa, 24. 
desde sus inicios noticias de actualidad, tanto nacionales -locales y regionalescomo internacionales, eventos sociales, acontecimientos políticos, notas de color, breves narraciones literarias y avisos publicitarios.

$\mathrm{Su}$ estilo estaba inspirado en el modelo europeo del magazine, un híbrido que reunía distintos géneros que se combinaban con las necesidades de los consumidores medios y populares ${ }^{13}$. Era un «semanario de variedades» ${ }^{14}$ a quien Rogers ${ }^{15}$ y Prieto $^{16}$ califican como «familiar». Según Prieto ${ }^{17}$, la revista exigía un alto grado de participación e identificación $\mathrm{y}$, a diferencia de los diarios, proponía un acto de lectura familiar o en grupo. Romano da cuenta, además, de que esta publicación no contenía espacios de crítica, sino que era un «acopio de lecturas entretenidas».

Para Ludmer ${ }^{18}$, Caras y Caretas ingresa en el género de la «enciclopedia cultural de la globalización de fin de siglo» y señala algunos de los rasgos por los que puede ser considerada como tal: espectro amplio y heterogéneo de lectores, masiva tirada - «Llegó la Caricareta, llegó la Caricareta», gritaban los diareros para ofrecer esta revista, que llegó rápidamente a los 100.000 ejemplares de tirada"19- y diversidad de mensajes. Su modernidad también radica en la variedad de su contenido:

Mezcla a los anarquistas con los liberales y a los radicales con los socialistas. Mezcla la ciencia, la literatura, la política y el periodismo de la época global, con los nuevos íconos de la cultura de masas; mezcla por lo tanto la cultura alta y la nueva cultura popular. Mezcla realidades y ficciones, y también lo escrito con lo gráfico y lo fotográfico, con la publicidad y con el mercado ${ }^{20}$.

13

Un detallado análisis sobre los antecedentes europeos que pudieron funcionar como modelo de $\mathrm{Ca}$ ras y Caretas puede consultarse en SARLO, B. (1985): El imperio de los sentimientos. Narraciones de circulación periódica en la Argentina, (1917-1927), Buenos Aires, Catálogos; Rogers, G. (2003): «Rasgos materiales y mundo de la producción en el semanario Caras y Caretas», Cuadernos del CISH, 13-14, La Plata, Universidad Nacional de La Plata - Facultad de Humanidades y Ciencias de la Educación; RIVERA, J. (2004): El escritor y la industria cultural, Buenos Aires, Atuel y RoMANO, E. (2004): Revolución en la lectura. El discurso periodístico-literario de las primeras revistas ilustradas rioplatenses, Buenos Aires, Catálogos, 57 y 298. Un fenómeno similar ocurre en el plano estético donde los modelos europeos eran imperantes. Sobre este último tema puede consultarse STEIMBERG, O.; TrAVERSA, O. (1997): Estilo de época y comunicación mediática, Buenos Aires, Atuel, 37.

14 MORAÑA, A. (2008): «La propaganda, la moda y el consumo en la revista Caras y Caretas (Argentina, 1898-1910)», Estudios. Revista de Investigaciones Literarias y Culturales, 32 (16), 249.

15 Rogers, G. (2003): «Rasgos materiales y mundo de la producción en el semanario Caras y Caretas», Cuadernos del CISH, 13-14, La Plata, Universidad Nacional de La Plata - Facultad de Humanidades y Ciencias de la Educación.

16 Prieto, A. (1988): El discurso criollista en la formación de la Argentina moderna, Buenos Aires: Sudamericana, 41.

17 Ibidem 17.

18 Ludmer, J. (1999): El cuerpo del delito, Buenos Aires, Perfil, 250.

19 Ulanovsky, C. (1997): Paren las rotativas. Historia de los grandes diarios, revistas y periodistas argentinos, Buenos Aires, Espasa, 24.

20 Ludmer, J. (1999): El cuerpo del delito, Buenos Aires, Perfil, 251. 
En razón de estas consideraciones, Ludmer ${ }^{21}$ considera que Caras y Caretas representa «la vanguardia del periodismo cultural».

Como lo indicamos anteriormente, con respecto a sus antecesoras se diferencia no sólo por su contenido, sino además por su formato: un logrado ensamble de texto e imagen que se combinaban en una heterogénea cantidad de materiales ${ }^{22}$. En cada tapa ofrecía una caricatura satírico-política que encontraba su interpretación en algún hecho coyuntural de la época. Además, la utilización de nuevas técnicas gráficas la colocaban por encima de otras publicaciones. Para Rogers ${ }^{23}$, las formas de producción, circulación y consumo hicieron que se diferenciara claramente de la prensa de la cultura letrada.

Romano ${ }^{24}$ considera, entre otras cosas, que la revista presentó una manera «revolucionaria» de leer, pues exigía la decodificación de elementos verbales e icónicos. Asimismo, el autor considera que parte de su éxito se debió a un notable equilibrio entre arte y mercado ${ }^{25}$.

En síntesis, Caras y Caretas fue una publicación que supo adaptarse a los intereses de una sociedad que había cambiado notablemente con la aparición de nuevos sectores sociales que se transformarían paulatinamente en el público de la revista.

En sus inicios se adquiría por suscripción. Es probable que este mecanismo haya determinado la escasa cantidad de avisos de los primeros números. Romano da cuenta de la existencia de dos tipos de ingresos: por suscriptores y el publicitario, sobre el que afirma:

El modesto, que ocupaba breve espacio, en blanco y negro, con el inevitable apelmazamiento de muchas otras ofertas en la misma página, y el lujoso, con variados colores y una dimensión destacada, lo cual les permitía incluir dibujos de mayor elaboración artística y textos generalmente versificados ${ }^{26}$.

A continuación, nos ocuparemos del análisis de los avisos versificados.

21 Ibidem, 278.

22 Romano, E. (2005): «La revolución en la lectura de masas», Revista Ñ, nro.72, Buenos Aires, Clarín, 14 y 168 .

23 Rogers, G. (2003): «Rasgos materiales y mundo de la producción en el semanario Caras y Caretas», Cuadernos del CISH, 13-14, La Plata, Universidad Nacional de La Plata - Facultad de Humanidades y Ciencias de la Educación.

24 Romano, E. (2005): «La revolución en la lectura de masas», Revista Ñ, nro.72, Buenos Aires, Clarín, 14.

25 Romano, E. (2004): Revolución en la lectura. El discurso periodístico-literario de las primeras revistas ilustradas rioplatenses, Buenos Aires, Catálogos, 168.

26 Ibidem, 185. 


\section{Los primeros avisos publicitarios de la revista Caras y Caretas (1898-1900): el aviso clasificado y la poesía como técnica publicitaria}

Es a partir de la reflexión de Romano que podemos caracterizar de forma más precisa los dos tipos de avisos que confluían en la publicación.

Por un lado, anuncios de tipo simple, compuestos por un texto breve, en general, oraciones independientes que brindaban información limitada sobre el producto o comercio promocionado. En algunos casos, el texto estaba acompañado por una ilustración que cumplía únicamente una función de soporte (Fig. 1). Los distintos elementos que constituían estos anuncios, lejos de formar parte de una estructura dinámica, se presentaban como un conjunto de segmentos que guardaban escasa relación entre sí. En lo referente a su formato, presentan una estructura similar a los avisos clasificados, característica señalada por varios autores como propia de la publicidad de fines del siglo XVIII y principios del siglo XIX ${ }^{27}$.

Por otro lado, el segundo tipo de avisos, a los que Romano caracteriza como «lujosos», estaban redactados en verso e incorporan estrategias discursivopersuasivas y visuales novedosas para los anuncios de la época. En función de sus características visuales y verbales deben estudiarse a la luz de la publicación en la que se insertan ya que muchos de sus rasgos se explican a partir de los rasgos estéticos de la revista (Fig. 2).

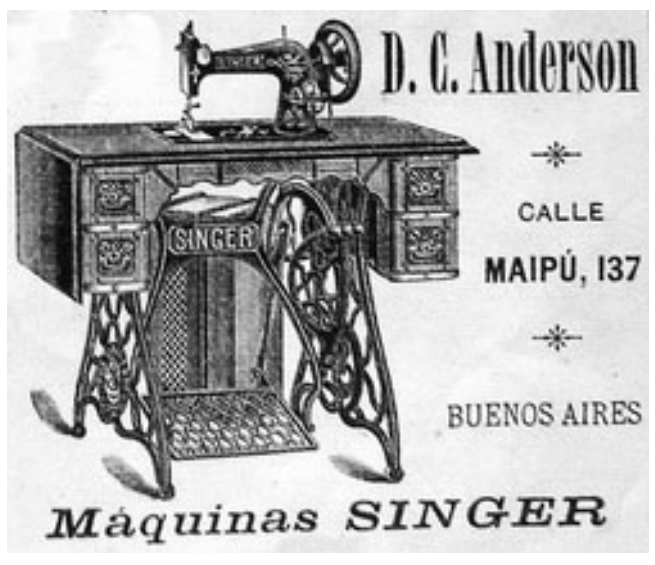

Figura 1

Caras y Caretas, 17-12-1898, nro.11

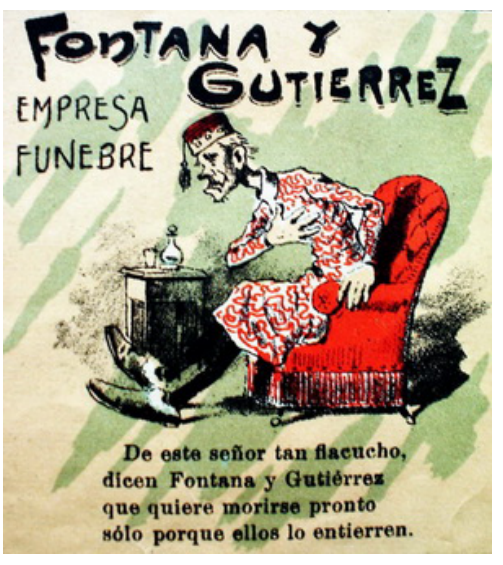

Figura 2

Caras y Caretas, 08-10-1898, nro.1

27 GotTI, M. (2005): «Advertising Discourse in Eighteenth-century English Newspapers'», en Skaffari, J.; Peikola, M.; Carroll, R.; Hiltunen, R.; Warvik, B. (eds), Opening Windows on Texts and Discourses of the Past, Ámsterdam, Benjamins, 23-38 y VEGA JimÉNEZ, P. (2008): «Estrategias publicitarias en Costa Rica (1900-1930)», Pensar la publicidad. Revista Internacional de Investigaciones Publicitarias, 2 (1), Madrid y Valladolid, 45-78. 
En ambos casos, los avisos publicitarios parecen no presentar un formato discursivo propio. Por el contrario, presentan similitudes con los avisos clasificados o con el estilo de la publicación. El abandono de estas formas y la configuración de la publicidad como un discurso de carácter persuasivo en sus niveles íconoverbales marcarán el inicio de la publicidad en sentido moderno y su independencia de otros formatos.

\section{Relaciones entre las portadas y los avisos publicitarios en verso de la revista Caras y Caretas}

\subsection{Avisos publicitarios en verso: entre la caricatura, el humor y la politica}

Distintos autores que han abordado el estudio de la revista Caras y Caretas han puesto su atención en este tipo particular de avisos publicitarios en virtud de lo atractivo de su construcción. Por un lado, Alonso Piñeiro ${ }^{28}$ señala la existencia de anuncios en verso y considera, aunque no con seguridad, que es un tipo de aviso que inaugura la revista para lograr efectividad. Posteriormente, enumera los autores que se encargaban de redactar los textos, que coinciden con los redactores e ilustradores de la publicación. Fraser ${ }^{29}$ también se refiere a los originales anuncios en verso de la revista, aunque no ofrece mayores precisiones.

Por su parte, Romero ${ }^{30}$ brinda detalles más precisos acerca de las características de este tipo de avisos. En distintas partes de su investigación hace referencia a la paulatina importancia que adquieren los anuncios en la revista y destaca el empleo de procedimientos literarios y plásticos, junto con aspectos políticos, en la construcción de los anuncios en verso. Considera que: «[...] el verso, la publicidad y lo político podían conjugarse. Un alarde de hibridez que evidencia hasta dónde esta revista fue el correlato ideal de una sociedad cuyos nuevos grupos sociales la volvían más heterogénea e imponían nuevas formas de convivencia». El mismo autor da cuenta, además, de la singularidad de estos anuncios al afirmar que el aviso en verso era: «el único de los lugares donde arte y mercado se entrecruzan» ${ }^{31}$.

28 Alonso PiñeIro, A. (1974:16): Breve historia de la publicidad argentina, Buenos Aires, Alzamor.

29 FrASER, H. (1987): Magazines and masks: Caras y Caretas as a reflection of Buenos Aires, 18981908, Tempe, Arizona State University - Center for Latin American Studies, 13.

30 RomAno, E. (2004): Revolución en la lectura. El discurso periodístico-literario de las primeras revistas ilustradas rioplatenses, Buenos Aires, Catálogos, 189.

31 Ibidem, 190. También puede consultarse sobre la incidencia de las distintas corrientes artísticas de la época, el excelente estudio de STEIMBERG, O.; TRAVERSA, O. (1997): Estilo de época y comunicación mediática, Buenos Aires, Atuel. 
Los avisos versificados tienen su antecedente en publicaciones europeas que fueron modelo para Caras y Caretas $^{32}$. Como lo indicamos al inicio de esta presentación, la revista fue caracterizada por distintos autores como un magazine inspirado en modelos europeos y es probable que haya tomado de ellos el formato de los anuncios en verso. De todos modos, la inclusión de poesía literaria -no publicitaria- tenía mucha presencia en los primeros años de la revista. En distintas secciones se incluían composiciones poéticas de autor o anónimas ${ }^{33}$. Con respecto a este tema, Romano ${ }^{34}$ afirma que paulatinamente se fue abandonado la poesía, género supremo de la revista, y que se prefirieron «los usos publicitarios, satíricos o encomiásticos del verso, a los eminentemente artísticos».

El empleo de versos en la prensa y en los anuncios data de largo tiempo. Sánchez Guzmán ${ }^{35}$, citando a García Ruescas, da cuenta de un periódico español de mediados del siglo XIX que: «Ponía en la cuarta plana unas gacetillas, a veces en verso, que eran una bendición de Dios, pues allí iban cultos, modas, chascarrillos y anuncios en el más disparejo revoltijo que darse puede».

En el mismo sentido, Romano ${ }^{36}$ brinda algunos ejemplos que pueden tomarse como un antecedente de estas composiciones. Entre ellos, una revista española que convoca a su dibujante y un redactor e «impone los anuncios en verso» (citando a Gómez Aparicio). Específicamente sobre Caras y Caretas, al referirse a los avisos de la revista considera que: «[...] Casi todas van acompañadas de unos versitos remotos antecedentes del jingle- que revelan un segundo empleo de esta técnica, pues el primero fue el verso satírico de la tapa». Asimismo, suma un dato de fundamental relevancia que permite establecer de qué modo en la producción de las distintas secciones que componían la revista se entrecruzan las fronteras estilísticas: «La confección plástica de los avisos no se aparta del estilo caricaturesco, pero manteniendo una cierta ilusión de perspectiva (...)» ${ }^{37}$.

Romano $^{38}$ ilustra el cruce literario y artístico a través de la presentación de un dibujo de Manuel Mayol, cofundador y principal dibujante de Caras y Caretas, que

32 También publicaciones posteriores utilizaron el mismo recurso. Por ejemplo, Pastor Martín realiza un interesante estudio sobre el empleo de la poesía como fórmula publicitaria en Segovia durante el período de la Guerra Civil Española (1936-1937). A estos avisos los considera como «atípicos textos publicitarios"». PASTOR MARTín, J. (2009): «Segovia, 1936-1937. La publicidad en los tiempos de la Guerra Civil», Pensar la publicidad. Revista Internacional de Investigaciones Publicitarias, 3 (1), 83-100 (83).

33 Rogers, G. (2007): «Escuela de aficionados. Lectores y letras de molde en la cultura emergente de 1900», Orbis Tertius, 12 (13), La Plata, Universidad Nacional de La Plata - Facultad de Humanidades y Ciencias de la Educación, 6.

34 RomAno, E. (2004): Revolución en la lectura. El discurso periodístico-literario de las primeras revistas ilustradas rioplatenses, Buenos Aires, Catálogos, 287.

35 SÁnChez GuZmán, J. (1976): Breve historia de la publicidad, Madrid, Pirámide, 115.

36 RomAno, E. (2004): Revolución en la lectura. El discurso periodístico-literario de las primeras revistas ilustradas rioplatenses, Buenos Aires, Catálogos, 188.

37 Ibidem, 190.

38 Ibidem, 261. 
aparece entre las páginas artísticas de la revista y, algunos números después, es utilizado como parte de una publicidad de tabaco. El autor se refiere en este caso a un «deslizamiento» que convierte arte en propaganda con mínimas modificaciones. Posteriormente, indica que las publicidades de la revista eran anónimas, pero que por sus características era probable que las redactaran los mismos escritores de la publicación. Los dibujantes participaban de la ilustración de los avisos puesto que aún no existían las agencias dedicadas a la actividad publicitaria, tal como se las conoce en la actualidad.

La particularidad de los avisos en verso radica en la incorporación de recursos visuales y discursivo-persuasivos novedosos e innovadores para la publicidad de la época, diferentes de los utilizados en el resto de los avisos publicitarios de la revista, como así también en otros tipos de textos incluidos allí.

Poseen como característica singular la inclusión de pasajes poéticos creados ad hoc y una ilustración que presenta un alto grado de interacción con el texto. Los pasajes poéticos se dan en una gran variedad de composiciones métricas (cuartetas, quintillas, redondillas, silvas, entre otras) que inciden en la organización de la información dentro del discurso. La necesidad de seguir las pautas de determinada composición origina la alteración del orden de los constituyentes de la oración, dando lugar a la focalización de distintos elementos. El contenido de estas composiciones refiere al producto ofrecido, en muchos casos, a través de un texto de tipo humorístico-político.

De acuerdo con su construcción discursiva, pueden ser clasificados en distintas categorías. En primer lugar, avisos que apelan directamente al lector a través del empleo de interrogaciones retóricas u oraciones de tipo exhortativo (Fig. 3); en segundo lugar, anuncios que se estructuran a partir de una instancia dialogal entre dos o más personajes que se refieren al producto, comercio o servicio ofrecido (Fig. 4); por último, composiciones que no apelan al lector y no incluyen diálogos, pero por su misma construcción presentan un alto grado de vinculación con la imagen que se coloca en el anuncio (Fig. 5 y 6). En este último caso, la comprensión del mensaje está dada por la interacción de ambos constituyentes.

La relación icónino-verbal entre los distintos segmentos de los avisos es muy estrecha. Al no funcionar únicamente como un soporte, la imagen es fundamental para comprender algunos pasajes del texto, aspecto que resulta de gran novedad para el período bajo estudio. Su dinamismo también se observa en la diversidad de figuras retóricas que pueden plasmarse en la imagen (hipérboles, enumeraciones, metonimias, etc. $)^{39} \mathrm{y}$, además, en su naturaleza, dotada de elementos plásticoformales que dan idea de movimiento.

39 MAGARIÑOS DE MORETín, J. (1991): El mensaje publicitario. Nuevos ensayos sobre semiótica y publicidad, Buenos Aires, Edicial y MADRID CÁNOVAS, S. (2006): Semiótica del discurso publicitario. Del signo a la imagen, Murcia, Universidad de Murcia, Servicio de Publicaciones. 


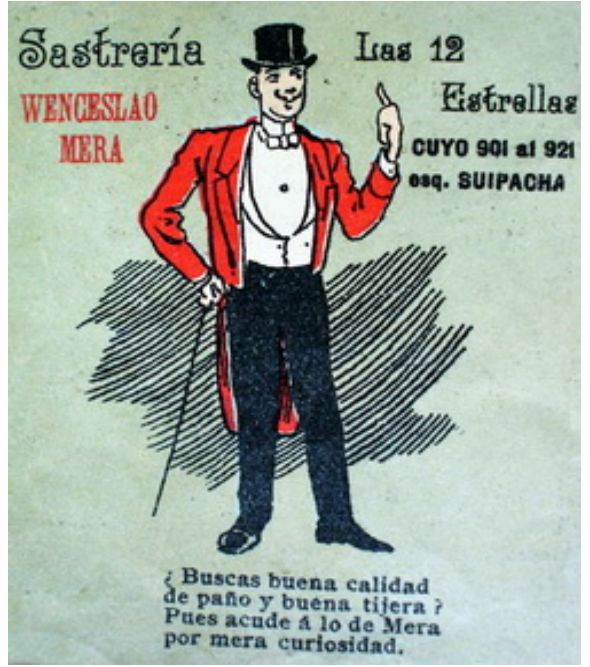

Figura 3

Caras y Caretas, 29-10-1898, nro.4

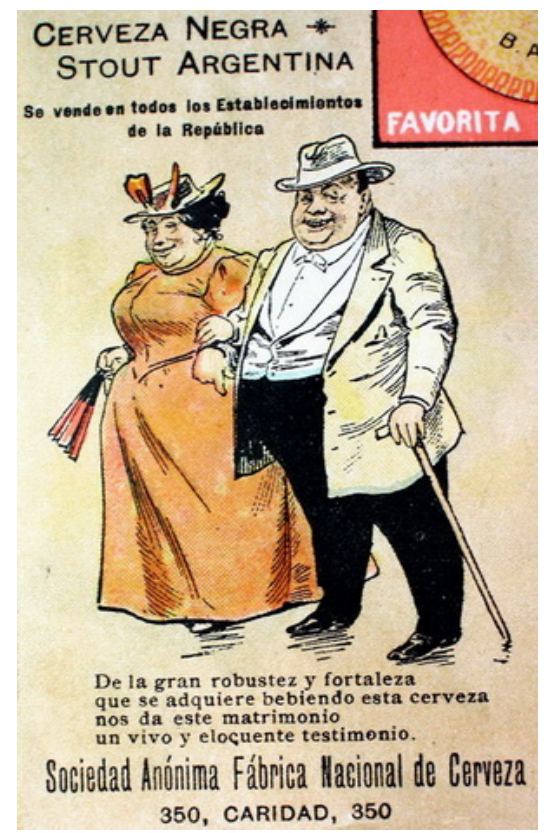

Figura 5

Caras y Caretas, 06-03-1899, nro.35

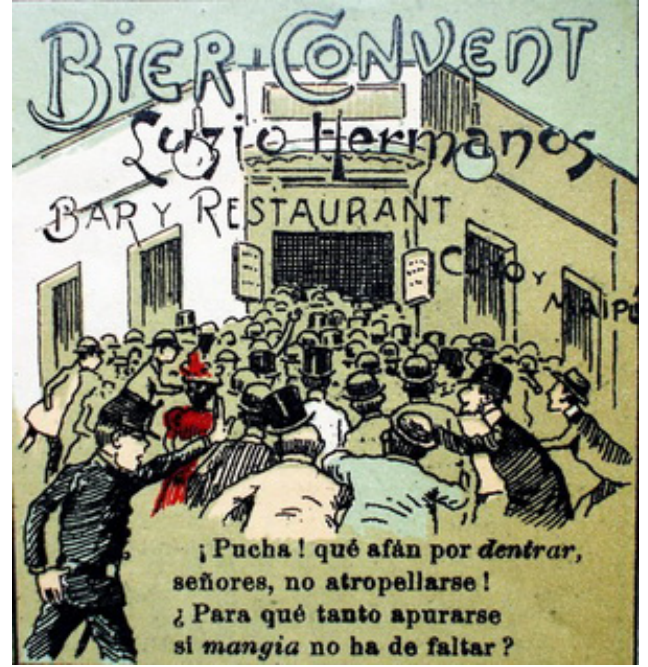

Figura 4

Caras y Caretas, 19-11-1898, nro.7

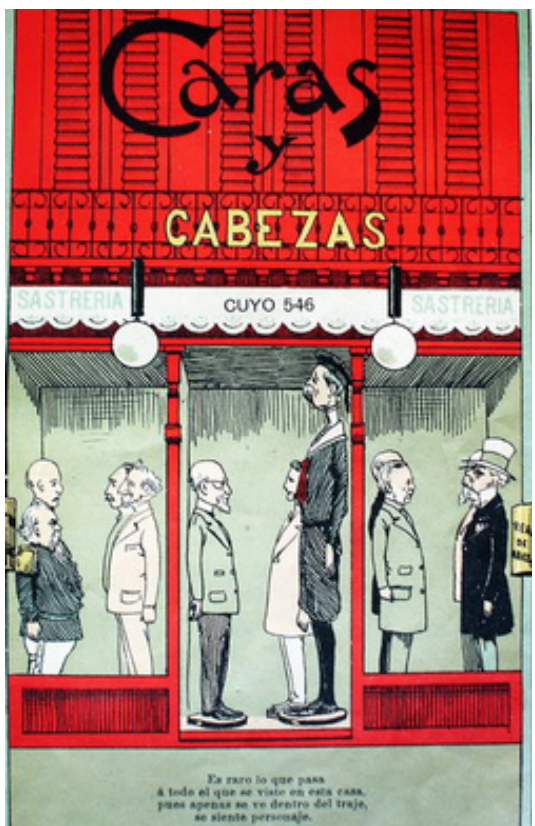

Figura $6^{40}$

Caras y Caretas, 22-10-1898, nro.3

40 Transcribimos a continuación el texto incluido en esta publicidad: «Es raro lo que pasa / a todo el que se viste en esta casa / porque apenas se ve dentro del traje / se siente personaje». 
En distintos grados, son necesarios elementos del texto para comprender el significado de la imagen y viceversa. Contribuyen a ello una serie de recursos verbales, como el empleo de deícticos («esta cerveza», «este matrimonio», «esta casa»), que requieren de las coordenadas visuales para ser interpretados en forma correcta.

En las fig. 3, 4 y 5 los gestos de los personajes ilustrados en la imagen muestran la idea de movimiento, ya sea de manos, brazos o piernas. En el caso de la fig. 6, los recursos formales y plásticos que dan idea de movimiento están ausentes puesto que lo que se quiere representar es precisamente la rigidez de las figuras que simulan ser maniquíes.

Las ilustraciones presentan rasgos visuales que permiten vincularlas con el estilo propio de la revista. Son dibujos de tipo humorístico que caricaturizan e hiperbolizan distintas situaciones. En el caso de la fig. 6 estos rasgos se combinan, además, con un contenido político evidente. Los maniquíes representan personalidades públicas de la época, fáciles de reconocer para el lector de la revista. En este anuncio, se produce, además, una identificación entre el aviso y la imagen del comercio promocionado - un recurso plástico común en este período ${ }^{41}$ - puesto que los modelos a los que hace referencia el texto se encuentran dentro de la vidriera del comercio publicitado. En el caso de la ilustración de la fig. 4, tanto la imagen como el texto reproducen una situación cotidiana de la época. En el aviso se muestra una escena representada por un grupo de inmigrantes que se amontonan para entrar a un bar. La mezcla de idiomas en el texto da cuenta de la compleja situación lingüística del momento ${ }^{42}$.

Desde el punto de vista de su construcción gramatical, estos anuncios están constituidos, como ya lo indicamos, por composiciones poéticas que forman la base del segmento verbal. En lo que respecta a la estructura interna, y a diferencia de los que sucede con el resto de los anuncios -construidos por oraciones de tipo independiente- podemos señalar la existencia de oraciones coordinadas y subordinadas (causales, concesivas, etc.). Además, por su misma estructura, los textos presentan un alto de grado conectividad. Por ejemplo, la recreación de una instancia dialogal condiciona la aparición de algunos elementos propios de situaciones orales que brindan coherencia al texto (conectores, organizadores textuales, uso de pronombres, etc.).

En cuanto al sistema verbal, en estas composiciones predomina el tiempo presente del modo indicativo, que le da actualidad e inmediatez al mensaje. En lo referente al tratamiento utilizado, aquellos anuncios que se dirigen directamente al lector o incluyen diálogos emplean la segunda persona del singular (tú) que se observa en las desinencias verbales (Fig. 3: «Pues acude a lo de Mera»). Se le suma a

41 Es probable que esto se deba a la importancia que habían adquirido las vidrieras en este período. Véase RoCCHI, F. (2000): «El péndulo de la riqueza: la economía argentina en el período 1880-1916», en Lobato, M. (dir.), Nueva Historia Argentina, tomo 5, Buenos Aires, Sudamericana.

42 Véase Fontanella de WeinBerg, B. (1987): El español bonaerense. Cuatro siglos de evolución lingüística (1580-1980), Buenos Aires, Hachette. 
esto, la inclusión de vocativos, que se registran en las interacciones entre los personajes (Fig. 2: «Señores»). A diferencia de lo que ocurre en otros anuncios, el mecanismo de la elipsis, producto de la condensación del texto, no tiene un uso particular.

Desde el punto de vista léxico-semántico, los avisos publicitarios analizados presentan una gran variedad de recursos (antítesis, repeticiones, metonimias, juegos de palabras, enumeraciones, voces opuestas, etc.) que en muchos casos aparecen en función de las restricciones impuestas por la métrica o condicionadas por aspectos específicos de los diálogos (Fig. 3: «Acude a lo de Mera por mera casualidad»). A pesar de la breve extensión de los textos, aparece la ponderación y exaltación de las cualidades del producto por medio de adjetivos de tipo calificativo en distintos tipos de construcciones (Fig. 3: «buena calidad y buena tijera»; Fig. 5: «gran robustez y fortaleza», «vivo y elocuente testimonio»).

Desde el punto de vista de los aspectos pragmáticos, podemos señalar, como ya lo indicamos, la inclusión de pronombres deícticos que, por su mismo funcionamiento, aluden a la situación de comunicación y el empleo de metáforas de la vida cotidiana $^{43}$. En coincidencia con estos usos, el registro empleado es informal y se caracteriza por la incorporación de términos coloquiales (Fig. 4: «¡Pucha! qué afán por dentrar»).

Las características discursivo-persuasivas y visuales de los anuncios publicitarios en verso enumeradas con anterioridad resultan, como ya lo indicamos, novedosas para la época. La originalidad se pone de manifiesto primordialmente por la inclusión de composiciones en verso de tipo humorístico y, en algunos casos, político, y de imágenes caricaturescas también vinculadas con lo político, como así también de una serie de estrategias textuales que no están presentes en otros avisos de la misma publicación.

Si bien algunos de los recursos verbales señalados con anterioridad -oraciones subordinadas, ponderación por medio de adjetivos, interacciones verbales, empleo de deícticos, metáforas de la vida cotidiana, figuras retóricas en la imagen, etc.aparecerán con posterioridad en el discurso publicitario gráfico, otros -como las composiciones poéticas de tipo humorístico, y en algunos casos político, y el empleo de caricaturas en las ilustraciones- desaparecerá al promediar los dos primeros años de publicación de la revista.

A la luz de estas consideraciones, no es posible admitir que la incorporación de estas técnicas en los avisos publicitarios sea producto de la evolución del discurso publicitario gráfico. Por el contrario, creemos que en su construcción inciden factores externos a la publicidad vinculados con el medio gráfico en el que se insertan. 


\subsection{Portadas en verso: entre la caricatura, el humor y la política}

El estilo de la revista se pone de manifiesto principalmente en las portadas, donde, por medio de la caricatura y de breves composiciones poéticas, se representaban distintas situaciones del ámbito político en forma de humor irónico (Fig. 7 y 8). El estilo de las portadas es uno de los aspectos que pone de relieve la nueva concepción de la revista en relación con el resto de las publicaciones de la época ${ }^{44}$.

Las tapas presentan ilustraciones caricaturescas de tipo humorístico-político y breves composiciones poéticas en una gran variedad de formas métricas que acompañan e interactúan con la imagen (Fig. 7 y 8). Sus características nos permiten establecer una relación especular con los avisos en verso. Existen rasgos formales y discursivos por medio de los que podemos señalar esta relación y confirmar las apreciaciones de los autores considerados en el apartado anterior que señalan cierta vinculación en base a la revisión superficial de ambos formatos.

En primer lugar, la interacción que se produce entre los elementos verbales e icónicos. La comprensión de la portada en su totalidad surge a partir de la puesta en consideración de ambos constituyentes y de la intervención de la coyuntura política y económica del momento. Un fenómeno similar detectamos en los avisos en verso. Tanto en la fig. 7, como en la fig. 8 se incorporan personajes políticos de la época que se identifican con su nombre propio (Carlos Pellegrini) o a través de alguna referencia indirecta en la caricatura y en el texto ( $«$...desde que Julio me dio su banda de Presidente» ${ }^{45}$ ). Al igual que los avisos en verso, las composiciones poéticas incluidas en las portadas pueden ser clasificadas en distintas categorías. En los ejemplos, colocamos una portada cuyo texto reproduce un monólogo del personaje ilustrado en la imagen (Fig. 7) y otra (Fig. 8), cuyo mensaje incorpora elementos del discurso religioso en forma paródica.

En su construcción, las ilustraciones suelen presentar un alto grado de interacción con el texto. Si bien en los ejemplos 7 y 8 se destaca la hipérbole, en el análisis completo de las portadas de los dos primeros años de publicación de la revista Caras y Caretas se encontraron una gran variedad de figuras (metáforas, personificaciones, antítesis, entre otras), similares a las detectadas en los anuncios en verso. Se le suma a esto que las imágenes están dotadas de elementos plástico-formales que dan idea de movimiento. En la fig. 7 las manos del personaje dibujado en la imagen y el flamear de la banda presidencial quitan rigidez a la figura; por su parte, en la fig. 8 , hay un juego con los planos, la sombra y la profundidad que producen la misma impresión. La idea de movimiento es otros de los rasgos en común que poseen las portadas y los anuncios en verso.

Desde el punto de vista de su construcción gramatical, las portadas presentan, como ya lo indicamos, composiciones poéticas que forman la base del texto. Se

44 CAVAlaro, D. (1996): Revistas argentinas del siglo XIX, Buenos Aires, Asociación Argentina de Revistas (AAER), 128.

45 Se refiere a la banda entregada por Julio Argentino Roca, quien fue presidente de la Argentina. 
observa la focalización de elementos, en función de las pautas métricas de la composición elegida. Como en los anuncios en verso, el sistema verbal que predomina es el presente del modo indicativo, también se incorporan breves narraciones (Fig. 7) y verbos en modo imperativo (Fig. 8: «Elévense», «mezcle»).

Desde el punto de vista léxico-semántico, las portadas analizadas presentan una gran variedad de recursos (antítesis, repeticiones, metonimias, juegos de palabras, enumeraciones, voces opuestas, etc.). Podemos señalar la existencia de juegos de palabras y voces opuestas («achicado», «agrandado»), como así también términos propios del discurso religioso («cielo», «armonía», «profecías», «mesías»).

Desde el punto de vista pragmático, los recursos se reiteran: metáforas de la vida cotidiana, interacciones verbales, empleo de registro informal y uso de deícticos (Fig. 7: «...me he agrandado yo»).

A partir de esta sintética descripción, podemos notar una similitud entre los recursos señalados con anterioridad en los anuncios en verso y los considerados en este apartado con respecto a las portadas.

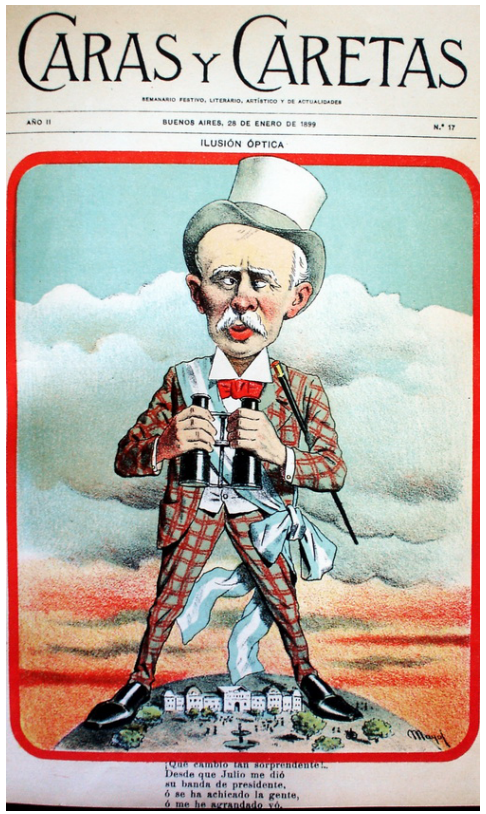

Figura $7^{46}$

Caras y Caretas, 28-01-1899, nro.17

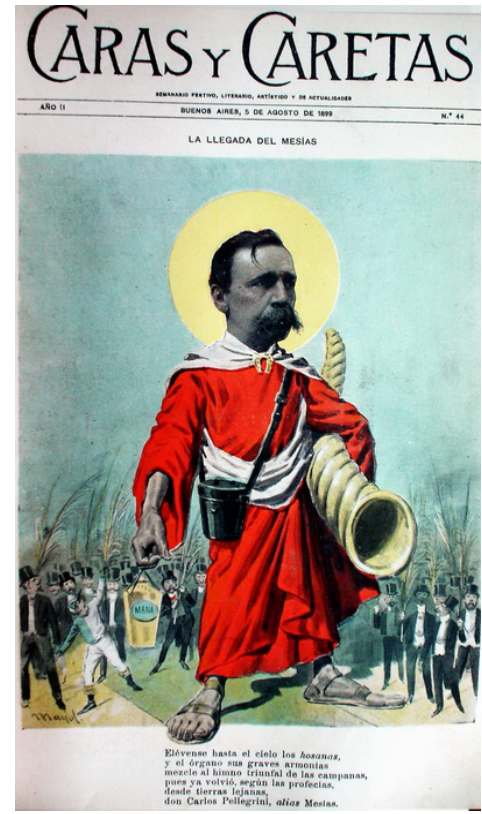

Figura $8^{47}$

Caras y Caretas, 05-08-1899, nro.44

46 Transcribimos a continuación el texto incluido en esta publicidad: «iQué cambio más sorprendente / desde que Julio me dio / su banda de presidente / ó se ha achicado la gente / ó me he agrandado yo».

47 Transcribimos a continuación el texto incluido en esta publicidad: «Elévense hasta el cielo los hosano / y el órgano sus graves melodías / mezcle al himno triunfal de las campanas / pues ya volvió, según las profecías / desde tierras lejanas / don Carlos Pellegrini, alias Mesías». 


\subsection{Avisos publicitarios en verso y portadas en verso}

Por último, para mostrar de modo más evidente las relaciones que se establecen entre las portadas de la revista Caras y Caretas y los anuncios en verso incluidos en la misma publicación, analizamos una portada y un aviso en verso que corresponden a un mismo número: 22-10-1898 (nro.3).

En la fig. 9, es posible observar el juego de palabras que se produce entre un fragmento del nombre de la revista -que se coloca en la parte superior del anuncio respetando la tipografía tradicional de la publicación utilizada en las portadas $(\mathrm{Ca}$ ras)- y el nombre del comercio: Cabezas. En segundo lugar, la inclusión de una composición poética y una imagen humorístico-política.

La composición presenta una estrecha relación con la imagen de modo que la comprensión del mensaje depende de la interacción de ambos constituyentes. El contenido humorístico-político -tanto de la imagen como del mensaje poético- son evidentes. Los personajes políticos y militares de la época forman parte de la vidriera del comercio y se intenta demostrar de forma humorística de qué modo se produce una transformación de los clientes que adquieren su vestimenta en el comercio $^{48}$. La imagen nos devuelve la ilustración de una vidriera comercial cuyo foco visual está representado por distintos maniquíes que reproducen a dichos personajes, uno de los cuales presenta una semejanza inconfundible con Ernesto Tornquist (vestido con sobretodo negro), un financista que cumplió un rol importante en la época.

En la fig. 10, correspondiente a la portada de la publicación, aparece en primer lugar el nombre de la publicación y luego la caricatura de Ernesto Tornquist, quien riega una rosa. La imagen de la rosa es una doble metáfora: refiere, por un lado, a la esposa de Ernesto Tornquist -Rosa Altgelt- y, por otro lado -en función de las afirmaciones del texto y del nombre que lleva impreso la maceta-, a su éxito en el campo de los negocios financieros, que crecen como una flor ${ }^{49}$.

En el texto se juega con el doble sentido y la ambigüedad que se basan en la comparación del riego de la rosa y la actividad comercial que desarrolla el personaje. En forma de humor irónico, el mensaje verbal funciona como una advertencia que se simboliza a través de los efectos que puede producir el riego excesivo.

La estrecha vinculación entre el aviso en verso y la portada se observa no sólo por la inclusión de la composición poética, los distintos recursos discursivo-

48 La referencia a las transformaciones de clase producidas por un cambio en la vestimenta es un recurso muy habitual en la publicidad de la época. Es probable que la reiteración de este aspecto se deba al deseo de algunos grupos de conseguir la anhelada movilidad social.

49 Con respecto al rol que cumplía Ernesto Tornquist en el gobierno, MADERO, F. (1980): «Ernesto Tornquist», en Ferrari, G. y Gallo, E., La Argentina del ochenta al centenario, Buenos Aires, Sudamericana, afirma: «[...] será durante la segunda presidencia de Roca [1898-1904] cuando Don Ernesto jugará su prestigio en tres cuestiones de singular importancia: la estabilidad de nuestra moneda, la unificación de la deuda externa, y la paz con Chile» (p.632). 
persuasivos y la representación humorística de hombres de la política, sino también por la reproducción de las letras del nombre de la revista en la parte superior del aviso en verso, en combinación con el nombre del comercio.

En síntesis, en ambos tipos discursivos se utilizan recursos similares, tanto icónicos como verbales que no se reproducen en otras secciones de la revista, como tampoco en el resto de los avisos publicitarios del mismo número.

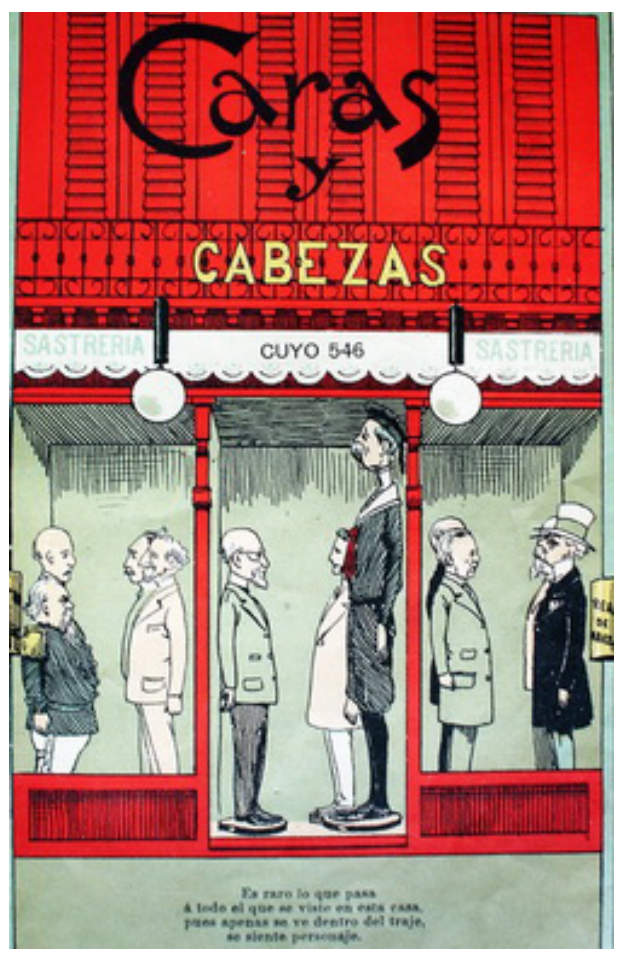

Figura $9^{50}$

Caras y Caretas, 22-10-1898, nro.3

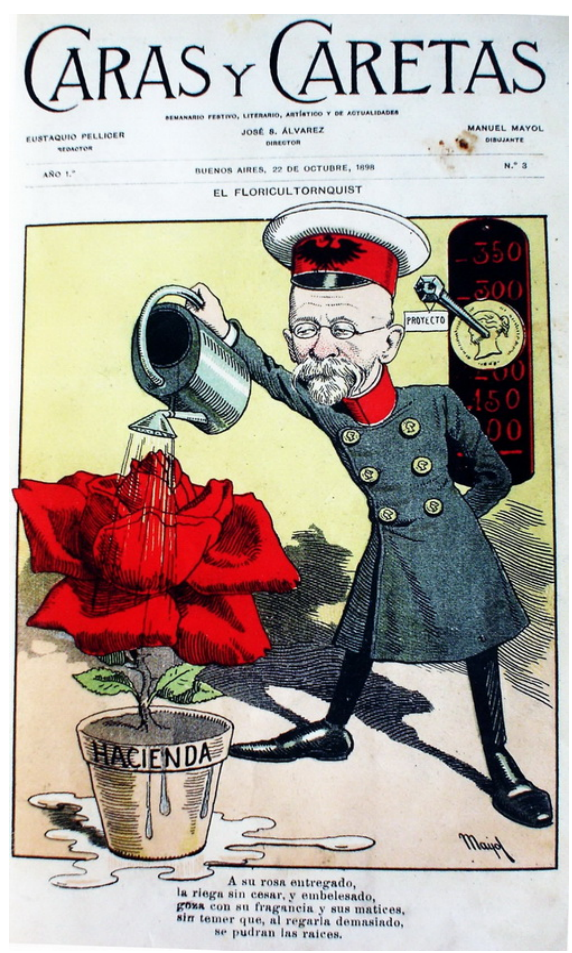

Figura $10^{51}$

Caras y Caretas, 22-10-1898, nro.3

\section{Conclusiones}

A fines del siglo XIX y los primeros años del siglo XX se produjeron una serie de transformaciones en la Argentina que modificaron radicalmente el perfil del país. Las publicaciones de la época no fueron ajenas a esta situación y dieron cuen-

\footnotetext{
50 Véase la nota 39.

51 Transcribimos a continuación el texto incluido en esta publicidad: «A su rosa entregado / la riega sin cesar, y embelesado, / goza con su fragancia y sus matices, / sin temer que, al regarla demasiado, / se pudran sus raíces».
} 
ta desde sus páginas de los acontecimientos ocurridos a nivel político, económico y social.

En este marco, comienza un proceso paulatino de cambio en el discurso publicitario que implica el abandono gradual de los avisos publicitarios similares a los anuncios clasificados y avisos simples, por avisos con características modernas. En la revista Caras y Caretas aparecen, además, anuncios publicitarios en verso en los dos primeros años de su publicación (1898-1900).

En todos los casos, los anuncios no presentan un formato discursivo propio. Por el contrario, presentan similitudes con los avisos clasificados o con el estilo de la publicación.

La inclusión de composiciones poéticas donde se emplean distintos recursos verbales, junto con imágenes caricaturescas, dan cuenta de un estilo publicitario novedoso y original para la prensa argentina de la época. La característica singular de estas composiciones fue su contenido político-humorístico puesto de manifiesto tanto a nivel verbal como visual, como así también de una serie de estrategias textuales que no están presentes en otros avisos de la misma publicación.

A lo largo de esta presentación, hemos tratado de demostrar que la novedad y originalidad de estos avisos no es producto de la evolución del discurso publicitario gráfico, sino que se debe, tal como quedó expuesto en el análisis, a la transferencia de las pautas de construcción de las portadas de la misma revista a los avisos. Situación que pone de manifiesto la dependencia de este tipo particular de anuncios publicitarios del medio gráfico en el que se insertan.

El abandono de estas formas y la configuración paulatina de la publicidad como un discurso de carácter persuasivo en sus niveles ícono-verbales marcarán el inicio de la publicidad en sentido moderno y su progresiva independencia de otros formatos.

\section{Referencias bibliográficas}

Alonso PiÑeIro, A. (1974): Breve historia de la publicidad argentina, Buenos Aires, Alzamor.

AuZA, N. (1989): «Las provincias ilustradas. 1887-1888», Res Gesta, Buenos Aires, Facultad de Derecho y Ciencias Sociales, Instituto de Historia, 25, enero-junio, 179-222.

Beyhaut, G.; Cortés Conde, R.; Gorostegui, H.; Torrado, S. (1961): Inmigración y desarrollo económico, Buenos Aires, Universidad de Buenos Aires - Departamento de Sociología.

CARO, A. (2009): «Una fase decisiva en la evolución de la publicidad: la transición del producto a la marca», Pensar la publicidad. Revista Internacional de Investigaciones Publicitarias, 3 (2), Madrid y Valladolid, 109-132.

CAvalaro, D. (1996): Revistas argentinas del siglo XIX, Buenos Aires, Asociación Argentina de Revistas (AAER).

CheCA Godoy, A. (2007): Historia de la publicidad, La Coruña, Netbiblo. 
Fontanella De WeinBerg, B. (1987): El español bonaerense. Cuatro siglos de evolución lingüistica (1580-1980), Buenos Aires, Hachette.

FRASER, H. (1987): Magazines and masks: Caras y Caretas as a reflection of Buenos Aires, 1898-1908, Tempe, Arizona State University - Center for Latin American Studies.

GAlván Moreno, C. (1944): El periodismo argentino. Amplia y documentada historia desde sus orígenes hasta el presente, Buenos Aires, Claridad.

GIESZINGER, S. (2001): The history of advertising language: the advertisements in The Times from 1788 to 1996, Frankfurt, Peter Lang.

GÖRLACH, M. (2002): "A linguistic history of advertising, 1700-1890», en Fanego, T. (eds), Sounds, Words, Texts and Change, Amsterdam, Benjamins, 83-104.

GÖRLACH, M. (2004): Text types and the history of English, Berlin and New York, Mouton de Gruyter.

GotтI, M. (2005): «Advertising Discourse in Eighteenth-century English Newspapers'», en Skaffari, J.; Peikola, M.; Carroll, R., Hiltunen, R.; Warvik, B. (eds), Opening Windows on Texts and Discourses of the Past, Ámsterdam, Benjamins, 23-38.

LAKOFF, G.; JoHnson, M. (1998): Metáforas de la vida cotidiana, Madrid, Cátedra.

LEECH, G. (1966): English in advertising. A linguistic study of advertising in Great Britain, London, Longmans.

Leiss, W.; Kline, S.; JHally, S.; Boterill, J. (2005): Social communication in advertising. Consumption in the mediated marketplace, 3 th. ed., London, Routledge.

LudMer, J. (1999): El cuerpo del delito, Buenos Aires, Perfil.

MAdERO, F. (1980): «Ernesto Tornquist», en Ferrari, G.; Gallo, E., La Argentina del ochenta al centenario, Buenos Aires, Sudamericana.

MAdRID CÁnOVAS, S. (2006): Semiótica del discurso publicitario. Del signo a la imagen, Murcia, Universidad de Murcia, Servicio de Publicaciones.

MAGARIÑos DE MoRetín, J. (1991): El mensaje publicitario. Nuevos ensayos sobre semiótica y publicidad, Buenos Aires, Edicial.

MorAÑA, A. (2008): «La propaganda, la moda y el consumo en la revista Caras y Caretas (Argentina, 1898-1910)», Estudios. Revista de Investigaciones Literarias y Culturales, 32 (16) 249-273.

OJEDA, A. (2009): «Del reclame a la publicidad. La transición hacia la modernidad publicitaria en la prensa periódica argentina entre 1862 y $1885 »$, Pensar la publicidad. Revista Internacional de Investigaciones Publicitarias, 3 (2), Madrid y Valladolid, 133-148.

PASTOR MARTín, J. (2009): «Segovia, 1936-1937. La publicidad en los tiempos de la Guerra Civil», Pensar la publicidad Revista Internacional de Investigaciones Publicitarias, 3 (1), Madrid y Valladolid, 83-100.

PRIETO, A. (1988): El discurso criollista en la formación de la Argentina moderna, Buenos Aires, Sudamericana.

RIVERA, J. (2004): El escritor y la industria cultural, Buenos Aires, Atuel.

RocCHI, F. (2000): «El péndulo de la riqueza: la economía argentina en el período 18801916», en Lobato, M. (dir.), Nueva Historia Argentina, tomo 5, Buenos Aires, Sudamericana, 15-69.

ROGERS, G. (2003): «Rasgos materiales y mundo de la producción en el semanario Caras y Caretas», Cuadernos del CISH, 13-14, La Plata, Universidad Nacional de La Plata Facultad de Humanidades y Ciencias de la Educación, 143-166. 
Rogers, G. (2007): «Escuela de aficionados. Lectores y letras de molde en la cultura emergente de 1900», Orbis Tertius, 12 (13), La Plata, Universidad Nacional de La Plata - Facultad de Humanidades y Ciencias de la Educación, 1-14.

Romano, E. (2004): Revolución en la lectura. El discurso periodístico-literario de las primeras revistas ilustradas rioplatenses, Buenos Aires, Catálogos.

Romano, E. (2005): «La revolución en la lectura de masas», Revista Ñ, 72, Buenos Aires, suplemento de Clarín, 14.

SÁnCHEZ GuZMÁn, J. (1976): Breve historia de la publicidad, Madrid, Pirámide.

SARLO, B. (1985): El imperio de los sentimientos. Narraciones de circulación periódica en la Argentina (1917-1927), Buenos Aires, Catálogos.

SteImberG, O.; TraVersa, O. (1997): Estilo de época y comunicación mediática, tomo I, Buenos Aires, Atuel.

Tungate, M. (2007): Adland: a global history of advertising, London, Kogan Page.

Ulanovsky, C. (1997): Paren las rotativas. Historia de los grandes diarios, revistas y periodistas argentinos, Buenos Aires, Espasa.

VEGA JiMÉNEZ, P. (2008): «Estrategias publicitarias en Costa Rica (1900-1930)», Pensar la publicidad Revista Internacional de Investigaciones Publicitarias, 2 (1), Madrid y Valladolid, 45-78. 